\title{
EDITORIAL
}

\section{Heat shock proteins in cardiovascular disease and the prognostic value of heat shock protein related measurements}

\section{A G Pockley, J Frostegård}

Heart 2005;91:1124-1126. doi: 10.1136/hrt.2004.059220

Are heat shock protein antibodies directly involved in the pathogenesis of cardiovascular disease?

A number of studies, including the article by Birnie and colleagues in this issue of Heart, ${ }^{1}$ have reported an association between increased concentrations of circulating heat shock protein antibodies and the severity and progression of cardiovascular disease. In addition, we and others have demonstrated that heat shock proteins, which are also present in the peripheral circulation, protect against rather than exacerbate cardiovascular disease. ${ }^{23}$ Are heat shock protein antibodies directly involved in the pathogenesis of cardiovascular disease, given that such antibodies and the proteins against which they are directed are present in the peripheral circulation of apparently normal individuals?

Heat shock or stress proteins are highly conserved molecules that fulfil a range of functions including cytoprotection and the intracellular assembly, stabilisation, folding and translocation of oligomeric proteins. ${ }^{4}$ Stress proteins are present in all species, and they are categorised into families that are named on the basis of their approximate molecular weight (for example, the $60 \mathrm{kDa} H s p 60$ ). Their synthesis can be induced by a range of cellular insults that induce protein unfolding, mis-folding, or aggregation and a flux of newly synthesised nonnative proteins; such insults include oxidative and haemodynamic stress, oxidised low density lipoprotein, ${ }^{5}$ and inflammatory cytokines, all of which are associated with the development of cardiovascular disease.

\section{HEAT SHOCK PROTEIN ANTIBODIES AND CARDIOVASCULAR DISEASE}

In addition to their role as molecular chaperones, heat shock proteins are immunodominant molecules, as a consequence of which a significant element of the immune response to pathogenic microorganisms is directed toward heat shock protein peptides that are derived therefrom. ${ }^{67}$ The phylogenetic similarity between microbial and mammalian forms of these molecules ( $\sim 50$ $80 \%$ identical residues in the case of the $60 \mathrm{kDa}$ family) has prompted the proposition that they could act as harmful autoantigens and that immune responses to heat shock protein epitopes from infectious agents might crossreact with equivalent "self" molecules and thereby establish a link between infection and various autoimmune disease conditions. ${ }^{68}$ The observations that elevated concentrations of antibodies to the $65 \mathrm{kDa}$ mycobacterial heat shock protein Hsp65 (which is $75 \%$ homologous to human $\mathrm{Hsp}^{\circ} 0^{\circ}$ ) are associated with the severity and progression of vascular disease, ${ }^{10-14}$ and that anti-Hsp65 antibody values predict the five year mortality of patients with carotid atherosclerosis ${ }^{15}$ and the incidence of cardiovascular events, ${ }^{16}$ support the proposition that immunity to heat shock proteins also influences the development and progression of cardiovascular disease. ${ }^{17} 18$ That antibodies to Hsp65 mediate endothelial cytotoxicity via crossreactivity with Hsp60 expressed on the surface of human endothelial cells after TNF- $\alpha$ or heat treatment, strengthens this proposition and suggests that endothelial injury resulting from such interactions might occur in vivo. ${ }^{19} 20$

Interest in the relation between circulating antibodies to "self" Hsp60 and cardiovascular disease has also developed, and the article by Birnie and colleagues in this issue of Heart ${ }^{1}$ extends previous work from a number of laboratories in this area. ${ }^{21-24}$ The authors report that patients admitted with acute cardiac chest pain and elevated values of anti-Hsp60 antibodies exhibited an adverse one year prognosis for coronary heart disease (CHD) related death or non-fatal myocardial infarction. ${ }^{1}$ This finding contrasts with the observations that anti-Hsp60 antibody concentrations do not predict cardiovascular events in adults, ${ }^{16}$ despite the fact that high concentrations of these antibodies are present in subjects with coronary artery disease (CAD)..$^{22}$ The additional observation by Birnie and colleagues that concentrations of anti-Hsp65 antibodies do not predict CHD related death or non-fatal myocardial infarction, ${ }^{1}$ combined with a previous report that anti-Hsp65 antibody concentrations are not significantly raised in patients with severe $\mathrm{CHD}^{23}$ suggests that the relation between raised concentrations of Hsp65 antibodies and cardiovascular disease might not be a universal one.

The lack of a relation between concentrations of antibodies to Hsp60 and Hsp65, despite the sequence homology of Hsp60 and Hsp65 reported by Birnie and colleagues, ${ }^{1}$ also questions the proposition that crossreactive or autoimmune Hsp60 responses contribute to disease progression, and data from other studies appear to support this. Autoantibodies to Hsp60 and antibodies to Hsp65 in the sera of patients with 
cardiovascular disease exhibit different epitope specificities ${ }^{25}$ and the concentrations of these antibodies do not correlate. ${ }^{23}$ In addition, the presence of raised concentrations of antibodies to chlamydial Hsp60, but not concentrations of antibodies to their human or Escherichia coli derived counterparts, is independently associated with CHD. ${ }^{26}$

It is clear that the literature in this area is varied, and the precise relation between circulating heat shock protein antibodies and the severity and progression of cardiovascular disease remains unclear. The reasons for the differing findings might result, in part at least, from the varied clinical statuses of the patient populations that have been investigated and monitored, as well as differences in the measurements that have been made. Antibodies to Hsp60 and antibodies to Hsp65 in the sera of patients with cardiovascular disease exhibit different complement activating ability, ${ }^{25}$ and the functional capacity of circulating antibodies might be a more relevant parameter to consider. Concentrations of complement activating antibodies to Hsp60 are raised in children from families that are at a high risk of developing cardiovascular disease, whereas concentrations of total IgG anti-Hsp60 and anti-Hsp65 antibodies are not related to the risk of developing cardiovascular disease. $^{24}$

\section{CIRCULATING HEAT SHOCK PROTEINS AND CARDIOVASCULAR DISEASE}

Another factor which might confound the perceived relation between circulating heat shock protein antibodies and the presence and severity of cardiovascular disease is the coexistence of heat shock proteins in the peripheral circulation, the presence of which has been reported by a number of investigators. ${ }^{23}{ }^{27-33}$ Circulating heat shock proteins appear to influence the progression of cardiovascular disease as increases in carotid intima-media thicknesses (a measure of cardiovascular disease) in subjects with established hypertension at a four year follow up have been shown to be significantly less prevalent (odds ratio 0.42) in individuals with high values of Hsp70 in their serum at enrolment. ${ }^{2} \mathrm{~A}$ similar, albeit non-statistically significant association between Hsp60 concentrations and the progression of cardiovascular disease was also observed (odds ratio 0.6). No relation between increases in carotid intima-media thicknesses and concentrations of anti-Hsp60 and antiHsp65 antibodies was observed, thereby further questioning the robustness of the relation between circulating heat shock protein antibodies and cardiovascular disease. A cross sectional study which measured serum Hsp70 concentrations in individuals evaluated for CAD by coronary angiography, and found that concentrations are significantly higher in patients without evidence of CAD, supports the proposition that heat shock proteins influence the progression of cardiovascular disease. ${ }^{3}$

The mechanism by which circulating Hsp70 influences the progression of cardiovascular disease is currently unclear; however, one possibility is that heat shock proteins interfere with, or in some way influence the activities of, their corresponding antibodies. As might be expected, soluble heat shock protein-heat shock protein antibody immune complexes are present in the peripheral circulation (unpublished observations). These complexes might influence the impact of circulating heat shock protein antibodies on the pathogenesis and progression of cardiovascular disease.

Although immune complexes are typically regarded as being pro-inflammatory activators of the complement system, the interaction of antigen presenting cells with soluble immune complexes reduces their production of the proinflammatory cytokine interleukin (IL)-12, enhances their production of the anti-inflammatory cytokine IL-10, and consequently induces an anti-inflammatory (immunoregulatory) adaptive immune $\mathrm{T}$ cell response. ${ }^{34}$ Given that such shifts in the qualitative nature of immune responses can attenuate atherogenesis in a number of experimental model systems, ${ }^{35-37}$ this might be a mechanism via which circulating heat shock protein-heat shock protein immune complexes could influence the progression of cardiovascular disease.

Although the relation between the concentrations of circulating heat shock proteins and cardiovascular disease suggest that these proteins might have some therapeutic potential, this remains to be demonstrated. It is the qualitative nature of the immune response to heat shock proteins which dictates their influence on disease progression, as subcutaneous immunisation with recombinant mycobacterial Hsp65 induces atherosclerotic lesions in normocholesterolaemic rabbits, ${ }^{38}$ normal C57BL/6J mice fed a high fat diet, ${ }^{39}$ and low density lipoprotein receptor deficient mice, ${ }^{40}$ whereas mucosal (oral, nasal) administration (which deviates immune responses toward a Th2 (immunoregulatory) phenotype) decreases atherosclerosis in experimental mouse models. ${ }^{36}{ }^{37}$ No studies have yet evaluated the therapeutic potential of "self" heat shock proteins.

\section{CONCLUSION}

It appears that the influence of circulating heat shock protein antibodies on cardiovascular disease depends on a number of factors in addition to their concentrations. The qualitative nature of these antibodies appears to be important, as might be their relation with circulating heat shock proteins. Further work is required in order to understand better the factors that drive the induction of heat shock protein antibodies and to clarify whether heat shock protein antibodies are active participants in the disease process. Changes in concentrations could be a consequence of as yet unidentified associations with the systemic inflammatory environment which is an inevitable feature of cardiovascular disease. Also required is a better understanding of the relation between heat shock protein antibodies and circulating heat shock proteins so that the influence of potentially anti-inflammatory soluble immune complexes can be fully evaluated. From these studies will come a better insight into the significance of heat shock proteins to cardiovascular disease and a better appreciation of the prognostic value of heat shock protein and heat shock protein antibody measurements.

\section{Authors' affiliations}

A G Pockley, Division of Clinical Sciences (North), Northern General Hospital, Sheffield, UK

J Frostegård, Department of Medicine and Centre for Infectious Medicine, and Centre for Metabolism and Endocrinology, Karolinska University Hospital and Karolinska Institutet, Stockholm, Sweden

Competing interests statement: The authors have no interests which conflict or compete with this article.

\section{REFERENCES}

1 Birnie DH, Vickers LE, Hillis WS, et al. Increased titres of anti-human heat shock protein 60 predict an adverse one year prognosis in patients with acute cardiac chest pain. Heart 2005;91:1148-53.

2 Pockley AG, Georgiades A, Thulin T, et al. Serum heat shock protein 70 levels predict the development of atherosclerosis in subjects with established hypertension. Hypertension 2003;42:235-8.

3 Zhu J, Quyyumi AA, Wu H, et al. Increased serum levels of heat shock protein 70 are associated with low risk of coronary artery disease. Arterioscler Thromb Vasc Biol 2003;23:1055-9.

4 Hightower LE. Heat shock, stress proteins, chaperones and proteotoxicity. Cell 1991;66:191-7.

5 Frostegård J, Kjellman B, Gidlund M, et al. Induction of heat shock protein in monocytic cells by oxidised low density lipoprotein. Atherosclerosis 1996; 121:93-103.

6 Kaufmann SHE. Heat shock proteins and the immune response. Immunol Today 1990;11:129-36. 
7 Young RA. Stress proteins and immunology. Ann Rev Immunol 1990;8:401-20.

8 Lamb JR, Bal V, Mendez-Samperio A, et al. Stress proteins may provide a link between the immune response to infection and autoimmunity. Int Immunol 1989;1:191-6.

9 Venner TJ, Gupta RS. Nucleotide sequence of mouse HSP60 (chaperonin GroEL homolog) cDNA. Biochim Biophys Acta 1990;1087:336-8.

10 Xu Q, Willeit J, Marosi M, et al. Association of serum antibodies to heat shock protein 65 with carotid atherosclerosis. Lancet 1993:341:255-9.

11 Birnie DH, Hood S, Holmes E, et al. Anti-heat shock protein 65 titres in acute myocardial infarction. Lancet 1994;344:1443

12 Hoppichler F, Lechleitner M, Traweger C, et al. Changes of serum antibodies to heat-shock protein 65 in coronary heart disease and acute myocardial infarction. Atherosclerosis 1996;126:333-8

13 Frostegård J, Lemne C, Andersson B, et al. Association of serum antibodies to heat-shock protein 65 with borderline hypertension. Hypertension 1997;29:40-4

14 Birnie DH, Holme ER, McKay IC, et al. Association between antibodies to heat shock protein 65 and coronary atherosclerosis. Possible mechanism of action of Helicobacter pylori and other bacterial infections in increasing cardiovascular risk. Eur Heart J 1998;19:387-94.

15 Xu Q, Kiechl S, Mayr M, et al. Association of serum antibodies to heat-shock protein 65 with carotid atherosclerosis. Clinical significance determined in a follow-up study. Circulation 1999;100:1169-74.

16 Veres A, Füst G, Smieja $M$, et al. Relationship of anti- $60 \mathrm{kDa}$ heat shock protein and anti-cholesterol antibodies to cardiovascular events. Circulation 2002; 106:2775-80.

17 Wick G, Xu Q. Atherosclerosis - an autoimmune disease. Exp Gerontol 1999:34:559-66.

18 Wick G, Perschinka H, Millonig G. Atherosclerosis as an autoimmune disease: an update. Trends Immunol 2001;22:665-9.

19 Schett G, Xu Q, Amberger A, et al. Autoantibodies against heat shock protein mediate endothelial cytotoxicity. J Clin Invest 1995;96:2569-77.

20 Mayr M, Metzler B, Kiechl S, et al. Endothelial cytotoxicity mediated by serum antibodies to heat shock proteins of Escherichia coli and Chlamydia pneumonia. Immune reactions to heat shock proteins as a possible link between infection and atherosclerosis. Circulation 1999:99:1560-6.

21 Zhu J, Quyyumi AA, Rott D, et al. Antibodies to human heat-shock protein 60 are associated with the presence and severity of coronary artery disease: evidence for an autoimmune component of atherogenesis. Circulation $2001 ; 103: 1071-5$.

22 Burian K, Kis Z, Virok D, et al. Independent and joint effects of antibodies to human heat-shock protein 60 and Chlamydia pneumoniae infection in the development of coronary atherosclerosis. Circulation 2001;103:1503-8.

23 Prohászka Z, Duba J, Horváth L, et al. Comparative study on antibodies to human and bacterial $60 \mathrm{kDa}$ heat shock proteins in a large cohort of patients with coronary heart disease and healthy subjects. Eur J Clin Invest 2001:31:285-92.
24 Veres A, Szamosi T, Ablonczy M, et al. Complement activating antibodies against the human $60 \mathrm{kDa}$ heat shock protein as a new independent family risk factor of coronary heart disease. Eur J Clin Invest 2002;32:405-10.

25 Prohászka Z, Duba J, Lakos G, et al. Antibodies against human heat-shock protein (hsp) 60 and mycobacterial hsp65 differ in their antigen specificity and complement-activating ability. Int Immunol 1999;11:1363-70.

26 Mahdi OS, Horne BD, Mullen K, et al. Serum immunoglobulin $\mathrm{G}$ antibodies to chlamydial heat shock protein 60 but not to human and bacterial homologs are associated with coronary artery disease. Circulation 2002;106:1659-63.

27 Pockley AG, Shepherd J, Corton J. Detection of heat shock protein $70(\mathrm{Hsp} 70)$ and anti-Hsp70 antibodies in the serum of normal individuals. Immunol Invest 1998;27:367-77

28 Pockley AG, Bulmer J, Hanks BM, et al. Identification of human heat shock protein 60 (Hsp60) and anti-Hsp60 antibodies in the peripheral circulation of normal individuals. Cell Stress Chaperones 1999:4:29-35.

29 Pockley AG, Wu R, Lemne C, et al. Circulating heat shock protein 60 is associated with early cardiovascular disease. Hypertension 2000;36:303-7.

30 Xu Q, Schett G, Perschinka H, et al. Serum soluble heat shock protein 60 is elevated in subjects with atherosclerosis in a general population. Circulation 2000;102:14-20.

31 Pockley AG, de Faire U, Kiessling R, et al. Circulating heat shock protein and heat shock protein antibody levels in established hypertension. $J$ Hypertension 2002;20:1815-20.

32 Lewthwaite J, Owen N, Coates A, et al. Circulating human heat shock protein 60 in the plasma of British civil servants. Circulation 2002;106:196-201.

33 Hunter-Lavin C, Hudson PR, Mukherjee S, et al. Folate supplementation reduces serum $\mathrm{Hsp} 70$ levels in patients with type 2 diabetes. Cell Stress Chaperones 2004;9:344-9.

34 Anderson CF, Lucas M, Gutierrez-Kobeh L, et al. T cell biasing by activated dendritic cells. J Immunol 2004;173:955-61.

35 Laurat E, Poirier B, Tupin E, et al. In vivo downregulation of T helper cell 1 immune responses reduces atherogenesis in apolipoprotein E-knockout mice. Circulation 2001; 104:197-202.

36 Maron R, Sukhova G, Faria A-M, et al. Mucosal administration of heat shock protein- 65 decreases atherosclerosis and inflammation in aortic arch of lowdensity lipoprotein receptor-deficient mice. Circulation 2002;106:1708-15.

37 Harats D, Yacov N, Gilburd B, et al. Oral tolerance with heat shock protein 65 attenuates Mycobacterium tuberculosis-induced and high-fat-diet-driven atherosclerotic lesions. J Am Coll Cardiol 2002:40:1333-8.

38 Xu Q, Dietrich H, Steiner HJ, et al. Induction of arteriosclerosis in normocholesterolemic rabbits by immunisation with heat shock protein 65 . Arterioscler Thromb 1992;12:789-99.

39 George J, Shoenfeld $Y$, Afek A, et al. Enhanced fatty streak formation in C57BL/6J mice by immunization with heat shock protein 65. Arterioscler Thromb Vasc Biol 1999; 19:505-10.

40 Afek A, George J, Gilburd B, et al. Immunization of low-density lipoprotein receptor deficient (LDL-RD) mice with heat shock protein $65(\mathrm{Hsp} 65)$ promotes early atherosclerosis. J Autoimmunity 2000;14:115-21.

\section{STAMPS IN CARDIOLOGY}

\section{Poster stamps}

A

nother excellent poster stamp with a cardiovascular design was issued in Germany fifty years ago to publicise the Sport and Health Exposition held in Berlin from $20^{\text {th }}$ June to $6^{\text {th }}$ July 1952. The heart and arterial and venous circulations are depicted in the stylised discus thrower underscoring one of the commonest themes of poster stamps-sporting events and the Olympics.

M K Davies

A Hollman

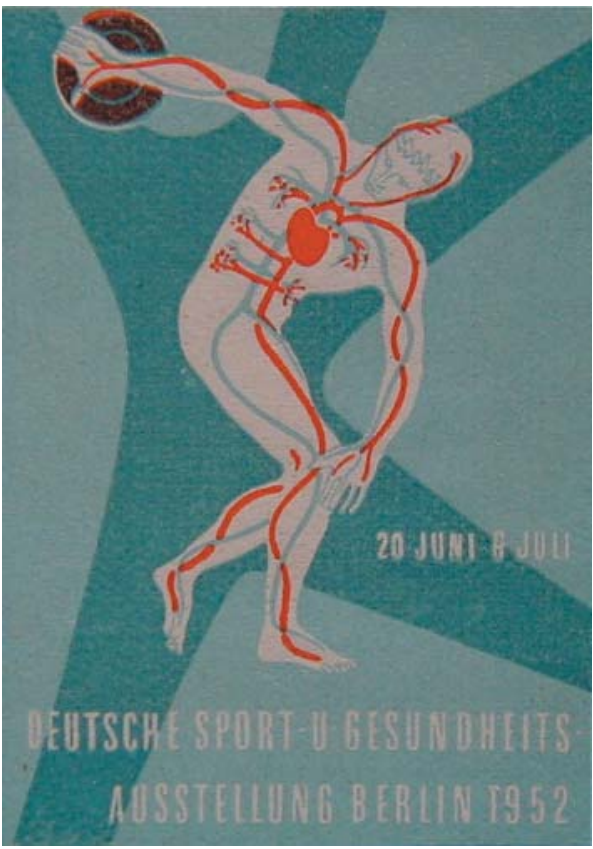

